\title{
The Use of Comic Book Style Reading Material in an EFL Extensive Reading Program: A Look at the Changes in Attitude and Motivation to Read in English in a Japanese University
}

\author{
Evan Jones \\ Kanda University of International Studies, Japan \\ kandaevan@gmail.com
}

\begin{abstract}
Many educators in the EFL field have faced a recurring problem of unmotivated participants unwilling to tackle the difficult task of acquiring reading proficiency in a foreign language (Day \& Bamford, 1998; Hitosugi \& Day, 2004). Many intensive reading programs involve assigning participants reading material that is thought to be of a suitable level and engaging to the student. Little thought is given to participants choosing their own reading material relevant to their own interests. Extensive reading programs attempt to address this issue by giving a choice of material. This report looks at the results of an extensive reading program in a Japanese women's university that incorporated comic book style reading materials into its extensive reading program. Changes in attitude and motivation of the participants are discussed, as well as possible future directions for this area of research.
\end{abstract}

Proficient reading in English is a crucial skill in today's modern world. The proliferation of the Internet and the spread of English as a lingua franca have meant that the development of reading skills can be a stepping stone for non-English speakers in terms of employment, cultural enrichment or integration into new cultures.

Anecdotal evidence based on the researcher's 12 years of teaching experience in Japan, at both the high school and university level, indicates that many participants lack motivation or confidence to acquire English reading skills. Many of the reading programs offered in these contexts focus on intensive reading programs. Students are not generally intrinsically motivated to read the materials used in such programs. In the researcher's experience, it has often been difficult to engage the participants in English reading in the classroom and even more difficult to motivate them to read outside the classroom.

In an attempt to increase Japanese participants' positive attitudes and motivation toward reading in English, the author developed an Extensive Reading (ER) program for first year participants at an all women's university in Japan. As the name suggests, ER is a reading program whereby participants read a wide variety of texts.

However, in the researcher's experience with ER programs in Japanese universities, while there was some evidence of increased student attitudes and motivation, ER was certainly not a panacea in itself. Participants, particularly those with lower English abilities, would often complain of the tedium of reading graded readers and the need to constantly refer to

Language Education in Asia, 2010, 1(1), 228-241. http://dx.doi.org/10.5746/LEiA/10/V1/A19/Jones 
dictionaries to confirm the meaning of new vocabulary. For this reason, the researcher decided to take a new approach by introducing comic book style graded readers into the ER program.

\section{Literature Review}

Previous research into ER programs in a language learning context (e.g., Day \& Bamford, 1998; Hitosugi \& Day, 2004; Krashen, 1982; Mason \& Krashen, 1997) has shown that ER programs can be beneficial in improving reading comprehension and motivation in previously poorly performing and de-motivated English participants. Takase (2009) found that the ER format of starting with simple texts and progressing to more difficult texts increases learner's motivation by building their confidence to read in a foreign language.

On a psycholinguistic level, research into learning has shown that multi-modal instruction and the use of contextual visual cues such as those found in comic book stories can be beneficial in regard to comprehension and schema formation (e.g., Kalyuga, Chandler, \& Sweller, 1999; Leahy, Chandler, \& Sweller, 2003; Meskill, 1996; Mayer \& Moreno, 1998; Moreno \& Mayer, 1999; Tindall-Ford, Chandler, \& Sweller, 1997). The benefits of contextual visual information are, however, more apparent to learners who have a low knowledge base of the subject matter (Clark, Nguyen, \& Sweller, 2006).

Although there has been considerable past research on the effects of ER on second language users, there is little in the literature regarding the use of comic books in an ER context. First language research has shown that the comic book format can be a useful medium to increase reading motivation (e.g., Haugaard, 1973; Krashen, 2005; Norton, 2003; Ujiie \& Krashen, 1996). Whilst considered "light" reading, studies have shown that readers of comics are also avid readers of more advanced texts, and the use of comic book style graded readers does not hinder motivation to seek out other literature (Cary, 2004).

Research into second language reading has also shown that familiarity with the content and format of the literature can increase student engagement with the text, in particular with Japanese participants and the manga format (Beals, 2009). Moreover, the authentic language used in translated manga has been shown to increase engagement with the text, which in turn motivates participants to further their reading of similar materials (Cary, 2004).

\section{Contextual Visuals and Schema Formation}

Using contextual visuals such as those found in comic book style material can be of substantial benefit to the second language reader, especially in the area of memory recall and schema formation. Schema formation is essentially the way memories and information are represented into different categories according to how they will be used. For example, in a restaurant, if someone says "sauce" the listener's restaurant schemata will be activated to understand that the word spoken was most likely "sauce" and not "source." Liu (2004) cites previous research (Levie \& Lentz, 1982; Levin, Anglin, \& Carney, 1987) when he outlines the five major functions of using contextual visuals in combination with written text:

Representation: Visuals repeat the text's content or substantially overlap with the text.

Organization: Visuals enhance the text's coherence.

Interpretation: Visuals provide the reader with more concrete information.

Transformation: Visuals target critical information in the text and recode it in a more memorable form.

Decoration: Visuals are used for their aesthetic properties or to spark readers' interest in the text. 
Liu (2004) goes on to make the point that, whilst decoration does not aid memory formation, the preceding four functions: representation, organization, interpretation and transformation are important functions in regard to aiding memory and schema formation. The visuals enhance the reader's ability to make connections with the written word and its meaning. By doing so, this greatly reduces the cognitive load on the working memory.

\section{Contextual Visuals and the Split Attention Effect}

Split attention occurs when two different sets of visual information must be attended to at the same time to form meaning (Clark et al., 2006). This usually results in working memory capacity being taken up with one set of information while the learner searches for the corresponding information from a separate location in the text. An obvious example of this is using a glossary of terms at the end of a book or a dictionary. If a novice language learner is trying to understand a text that has highly specialized or foreign vocabulary, then the mental effort expended to refer to the back of the book or dictionary, search for the relevant word and then attend to the definition will take up valuable working memory capacity. If a student is provided with a visual context along with the text, as with comic books, to arrive at a meaning, then this can mean a substantial lessening of the need for the use of a glossary or dictionary, and therefore of the split attention effect. Dictionaries and glossaries are of benefit to the second language learner; however, their cumbersome usage can be an impediment to the enjoyment of reading because of the split attention effect that its usage induces.

\section{Contextual Visuals and Their Use in Memory Formation}

It is important to look into research regarding how the human mind encodes sensory information into memory, as essentially, memory is knowledge. The modal model is one of the most well known and accepted models of the cognitive processes involved in the human memory system (Baddeley, 1999). Over the years, there have been several different modal models proposed by academic researchers. One characteristic common to all, however, is the belief that the human memory system consists of three distinct types of memory. The three systems, sensory memory, short term or working memory, and long term memory, are all linked in a uni-directional and linear process. Figure 1 shows an early influential modal model proposed by Atkinson and Shiffrin (1968). Most subsequent models are basically variations of this.

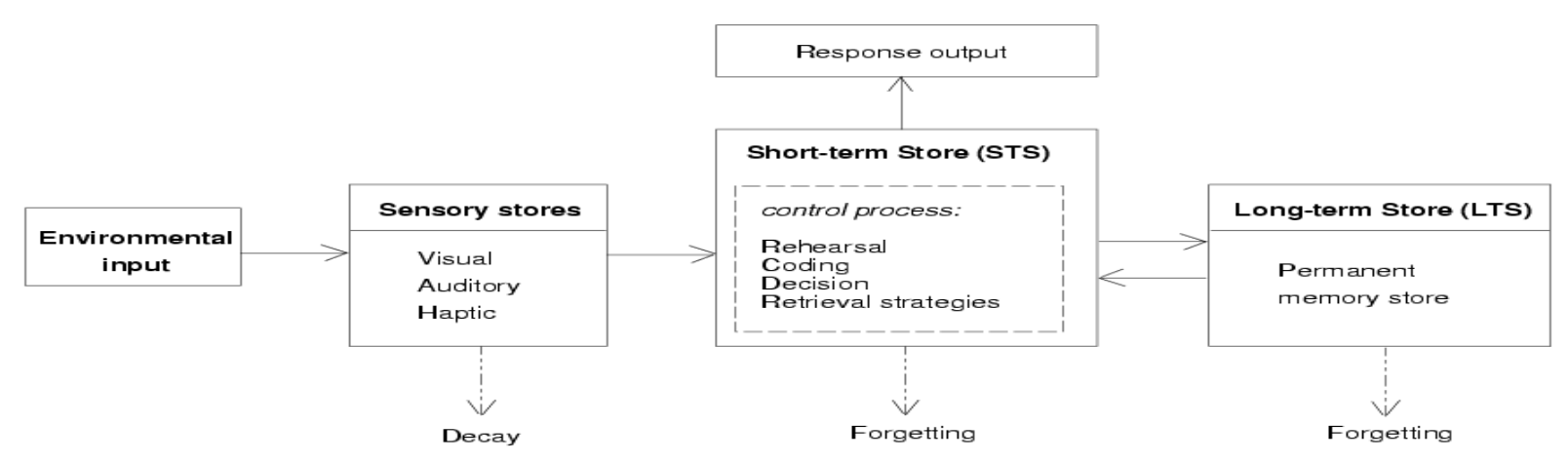

Figure 1. The modal model of human memory.

The first type of memory system, sensory memory, has the most limited capacity of the three types. It is thought we only have up to three seconds of memory capacity before information is either attended to or lost forever (Baddeley, 1999).

Short term memory, or working memory, is the second stage of processing in the modal model. Short term memory plays a much different role and has a much larger, although still limited, 
capacity than sensory memory. Recognition of the importance of short term memory can be traced back to Miller's seminal 1956 publication, "The Magical Number Seven, Plus or Minus Two: Some Limits on Our Capacity for Processing Information." In this research, Miller found evidence that humans cannot retain more than approximately seven individual pieces of information in short term memory. Any more than this is lost and cannot be processed.

Short term memory has a time limit capacity as well. Thirty seconds is generally considered to be the average time limit for information stored in short term memory if there are not additional chunks of information being processed at the time. If more information chunks are being introduced to the short term memory, then they will interfere with the other stored memories and cause memory loss to be far more rapid (Baddeley, 1999).

Despite the wealth of literature supporting the use of contextual visuals in schema formation and memory formation, there has been little research conducted to find if contextual visuals affect EFL participants' motivation and attitudes toward reading. The purposes of this study are thus:

1. To examine/explore changes in participants' attitudes toward an extensive English reading program throughout a semester.

2. To examine the effects of using comic book style graded readers on participants' motivation to read English.

\section{The Study}

The research sample of twenty-five was taken from one first semester Freshman English class at Hiroshima Bunkyo Women's University. The participants attended two ninety-minute communicative-based English classes a week.

A pre-project questionnaire in Japanese (see Appendix A for an English translation) was administered to the participants. The survey was designed to gauge participants' attitudes toward reading in both English and Japanese. Participants were asked to rate the necessity of reading in English and their reasons for the ranking; they were also asked to discuss their feelings about embarking on their first ER program.

A post-project questionnaire in Japanese (see Appendix B for an English translation) was also administered to measure any changes in participants' attitudes about reading in English and Japanese over the semester. Participants' attitudes toward the ER project as well as their responses to the use of the comic book style material were also recorded.

The pre- and post-program questionnaires were administered in Japanese so the participants could fully understand the questions and also be expansive in their responses. The responses were translated into English for the purpose of data analysis.

\section{Sample Class}

The sample used for this study were female native Japanese speakers between the ages of 19 and 20 who attended a compulsory general English course complimentary to their major studies. The sample was taken from the Early Childhood Education (ECE) major. The ECE majors were selected as their potential career path after graduation is elementary school teaching in the Japanese education system. Recent changes to the Japanese elementary school curriculum mean that elementary schools now include a compulsory English learning component. All ECE graduates in Japan are now expected to teach basic English skills as part of their classroom curriculum. The rationale behind using ECE majors as opposed to other majors (such as welfare, psychology, or nutrition) was to investigate a somewhat homogenous group 
with similar extrinsic motivation to attain a level of competency in English reading comprehension skills.

The participants' level of English proficiency ranged from beginner to false beginner. The English program at the university had only been introduced to the school the previous year.

Prior to that, there were no compulsory English classes as part of the university's curriculum. As the university does not specialize in foreign languages, it has previously not attracted participants who have achieved high grades in high school English.

The research was not conducted until the second semester, as it was felt that learners' English proficiency was not at a high enough level in semester one. It was also felt that the participants needed time to adjust to the demands of tertiary English studies, in particular the English only policy in the classroom.

\section{Texts}

The texts used in this study were from the Oxford University Press Graded Readers selection. This series of texts has been adapted or "graded" to match the reader's comprehension level. The grading starts from the "starter" level to level six. Participants were allowed to select their own readings starting from the starter level. Participants read three starter level comic books and then progressed to higher levels at their own discretion. The rationale for using this series was the availability of the comic book style at the starter level. The comic book style was not available after the starter level, however. Multiple copies of the series were available in the university's Self Access Learning Centre (SALC). The syllabus of the readers is also designed to facilitate a gradual increase in participants' reading development. The length of the stories and the complexity of the vocabulary increases with each additional grade level. It was also felt that the large variety of titles and genres would appeal to the interests of the class.

\section{Literature Circle Discussion Groups}

Participants met once a week for a 20-30 minute in-class group discussion about the texts they had been reading. The participants were placed in groups of three or four and were instructed to discuss their reading with each other. All group members had the same book to discuss. The teacher did not lead the discussions, but was available in class to answer student questions. Most questions directed to the teacher were related to vocabulary items. Participants were encouraged to discuss amongst themselves any questions or issues they had regarding the plot or characterization. Participants were encouraged to relate events and issues in the texts they read to their own experiences, as well as to critically engage with such events and issues.

\section{Reading Logs}

Reading logs have been found to encourage participants to move toward "critical appreciation" of texts (Carlisle, 2000). Having participants interact with the text while reading, which is one function of reading logs, encourages creativity and critical thinking (Kim, 2003). It was hoped that having participants complete reading logs would encourage them to have a deeper engagement with the texts.

Each student was instructed to complete a separate reading log for each graded reader. These were completed and handed in at varying intervals, depending on the length and difficulty of the text. Initially, participants were given a simplified reading log that asked for a summary of the text and a brief description of any connections they may have experienced with the story. After the first three comic book style readers, the participants were then given a more detailed log and they were instructed to write down their thoughts and impressions of the text, instead of a summary of what they had read. An example of an appropriate entry was provided on 
each reading log to provide modeling for the participants. The rationale behind this change in focus was to provide a more authentic experience for the participants, as Day and Bamford (1998) note that "summaries are not particularly interesting for the student to write" (p. 142). Dupuy, Tse and Cook (in Day \& Bamford, 1998, p. 142) also make the point that "students know that in the real world, people who read for pleasure do not do worksheets or write summaries of what they read."

Grading of the logs was generally done by the teacher ticking appropriate entries and writing a plus symbol to indicate particularly good responses, including responses that attempt to critique the text. If the student had written a simple summary of the storyline, then a written comment was used to indicate that it was not of sufficient depth. In keeping with the ideals of reading for pleasure, the participants were not given tests or asked to provide comprehension responses that could be judged either correct or incorrect.

\section{Results}

\section{Pre-Project Survey Results}

The pre-project student survey results indicated that an ER program combined with the use of comic book style graded readers had an overall positive effect on second language learners. The pre-project questionnaire also unearthed some interesting findings. Firstly, $32 \%$ of the participants in the class said that they disliked reading, even in Japanese. The majority of the participants $(60 \%)$ also indicated that they were not big readers in Japanese, reading less than one book per month.

The participants were also surveyed about their attitudes toward reading in English.

Surprisingly, $44 \%$ of the class had a positive view toward reading in English. Asked to elaborate, most responses tended to express the joy of discovering and understanding the new language. The more than half who held a negative view predictably indicated that their lack of English vocabulary and the frequent need to resort to dictionaries made reading in English a frustrating experience.

The vast majority of participants (96\%) thought that reading in English was necessary. When asked to explain their answers, many participants explained that globalization and the changing culture of Japan meant that competency in English was becoming a valuable skill in modern Japan. Only two participants felt that reading was the weakest of their macro-skills in English. Many participants considered grammar their weakest skill, followed by listening and conversation.

Participants were also asked to express their opinions about starting the English ER program. Of the 20 responses, five expressed reservations about starting the program. The responses were generally simple: "It's hard" or "It's depressing because I'm not good at it." Some thought that it would be fun, but with the caveat that only if they could easily understand the text.

\section{Post-Project Survey Results}

The results of the post-project questionnaire also produced some interesting findings. The number of participants who had expressed a positive view toward reading in English decreased from $68 \%$ to $64 \%$. The largest fall was from participants who said they "really enjoyed" reading in English, which decreased from 28\% to 16\%. The percentage of participants who held a positive or very positive view of reading in English decreased from $44 \%$ to $40 \%$.

Of particular interest to this research were the participants' attitudes to the comic book style readers. Eighty-four percent of the participants held a positive view of the comic book style 
readers. While participants offered various reasons for their preference for comic book style reading material, 11 respondents expressly claimed that the use of illustrations helped them ascertain the meaning of unfamiliar vocabulary.

The participants were also asked if they had experienced any changes in attitude toward reading after the ER program. Twelve participants answered that they had experienced no changes in attitude. However, the twelve other responses indicated that the participants had enjoyed the experience and were in fact motivated to read more books in English as a result.

\section{Discussion}

\section{Research Purpose 1}

1. To examine/explore changes in participants' attitudes toward an extensive English reading program throughout the semester.

The results of the post-program questionnaire indicated that some participants had changed their attitudes toward the ER program over the semester. From the results, it can be seen that participants had a slightly more negative attitude toward both reading in general and reading in English. However, the factors that attributed to this change are unclear. Was it the use of the comic book format or was it from the ER process itself? The participants had not been exposed to the literature circles format before entering university nor had they used reading logs in high school. These factors could have played a role in changing participants' attitudes and motivation and are worthwhile areas of follow up study.

Also apparent is the limited exposure that the participants had to the ER program. The ER program was only observed for one semester. Krashen (2004) reports that research has found that ER programs can take up to a year before measurable positive changes are apparent in regard to reading fluency and comprehension. It would be interesting to make follow up observations of the participants after one year to see if motivation and attitudes toward reading in English were improved. Further to this, would participants also be more inclined to progress to more difficult texts, in particular non-illustrated texts?

\section{Research Purpose 2}

2. To examine the effects of using comic book style graded readers on participants' motivation to read English.

Even though the results indicated the participants had a more negative attitude toward reading, the results from the post-program survey indicated that the comic book style readers were popular with the majority of the participants and motivated most of them to engage in further reading of English. This result was very encouraging, especially considering the low level of English ability of the participants. When asked why the participants enjoyed reading the comic book style readers, 11 of the participants indicated it was because the illustrations had helped them to ascertain meaning for the unknown vocabulary. This response lends support to the argument that illustrations are helpful in activating schemata. It also supports the argument that comic book readers can help to lessen the problem of the split attention effect.

Whilst tentative conclusions can be made from the results of the surveys, certain limitations are evident. The sample size of 25 participants represented only about $8 \%$ of the entire first-year student body at the university. In addition, the participants selected were majoring in early childhood education and could thus be expected to have a higher motivation to improve their English reading skills than, for example, nutrition or psychology majors. Would using comic book style reading material have a similar motivating effect on participants whose majors did not generally lead to work requiring a competency in English? 
The availability of suitable material was also an issue. The Oxford publications were chosen simply because there was very little else available. Although the results showed that the participants responded favourably to the material, the subject matter and the scope of topics were still limited. The participants could not progress beyond the starter level of reading materials in the comic book format. Whilst graphic novels aimed at ESL readers are available, their level was deemed too difficult for the participants.

The issue of dictionary use whilst reading and the corresponding increase in split attention effect was an area that could be explored more thoroughly. Some participants indicated in their survey responses that they could form the meaning of unknown text through the contextual visuals alone; however, more specific questions regarding dictionary use would have been useful in gauging what effect the visuals had in eliminating the split attention effect.

\section{Conclusion}

The use of comic book style readers and the participants' response to them lends support to previous research that contextual illustrations and context help enable participants' schema formation and general comprehension of text. This results in less reliance on distracting dictionary use and hence less split attention effect. The participants indicated that they enjoyed the experience of reading the comic books and were more motivated to read more comic books in English. Moreover, participants indicated that the principles of the reading program, especially choice of material and a realistic skill level, contributed to the participants' overall enjoyment of the ER program.

On the basis of the survey results, however, it can be concluded that the ER program did not improve participants' attitudes toward reading in English. In addition, the participants involved in the study indicated that their motivation to read English material had slightly decreased.

Further research and an expansion of the ER program is required to see if the positive results of the program can be applied to the wider student body of the university. The introduction of the comic book style readers has shown there is potential for their use as a tool for EFL teachers looking to increase their students' enjoyment of reading in English.

\section{Biodata}

Evan Jones is a lecturer at Kanda University of International Studies in Chiba, Japan. He is currently completing a Doctorate in education with the Queensland University of Technology in Brisbane, Australia. His research interests include EFL reading and cognitive load theory.

\section{References}

Atkinson, R. C., \& Shiffrin, R. M. (1968). Human memory: A proposed system and its control processes. In K. W. Spence, \& J. T. Spence (Eds.), The psychology of learning and motivation, Vol. 2 (pp. 89-195). New York, NY: Academic Press. Retrieved from http://sps.nus.edu.sg/ huyihuyi/pub/sp2171/node10.html

Baddeley, A. D. (1999). Essentials of human memory. Hove, England: Psychology Press.

Beals, C. (2009). ESL 578 Research Paper: Using Comics and Graphic Novels in the ESL Classroom. Retrieved from http://seratsuki.googlepages.com/comicsreading.pdf

Day, R., \& Bamford, J. (1998). Extensive reading in the second language classroom. Cambridge, England: Cambridge University Press.

Carlisle, A. (2000). Reading logs: An application of reader response theory in ELT. ELT Journal, 54(1), 12-19. Oxford, England: Oxford University Press.

http://dx.doi.org/10.1093/elt/54.1.12 
Cary, S. (2004). Going graphic: Comics at work in the multilingual classroom. Portsmouth, NH: Heinemann.

Clark, R., Nguyen, F., \& Sweller, J. (2006). Efficiency in learning: Evidence-based guidelines to manage cognitive load. San Francisco, CA: John Wiley \& Sons.

Dupuy, B., Tse, L., \& Cook, T. (1996). Bringing books into the classroom: First steps in turning college-level ESL students into readers. TESOL Journal, 5(4), 10-15

Furukawa, M. (2005). Another look at extensive reading: A study of Japanese university EFL participants (Unpublished master's thesis). Hyogo University, Kakogawa, Japan.

Retrieved from

http://repository.hyogou.ac.jp/dspace/bitstream/10132/1659/1/ZB30102006.pdf

Haugaard, K. (1973). Comic books: A conduit to culture? Reading Teacher, 27, 54-55.

Hitosugi, C., \& Day, R. (2004). Extensive reading in Japanese. Reading in a Foreign Language, 16(1), 91-110.

Kalyuga, S., Chandler, P., \& Sweller, J. (1999). Managing split-attention and redundancy in multimedia instruction. Applied Cognitive Psychology, 13(4), 351-357.

http://dx.doi.org/10.1002/(SICI)1099-0720(199908)13:4<351::AID-ACP589>3.0.CO;26

Kim, H. R. (2003). Literature circles in EFL curricula: Establishing a framework. The English Teacher, 32, 1-15. Retrieved from www.melta.org.my/ET/2003/2003-1.pdf

Krashen, S. D. (1982). Principles and practice in second language acquisition. New York, NY: Prentice Hall.

Krashen, S. D. (2004). The power of reading ( $2^{\text {nd }}$ ed.). Portsmouth, NH: Heinemann.

Krashen, S. D. (2005). The "decline" of reading in America, poverty and access to books, and the use of comics in encouraging reading. Retrieved from www.sdkrashen.com/articles/decline_of_reading/index.html

Leahy, W., Chandler P., \& Sweller J. (2003). When auditory presentations should and should not be a component of multimedia instruction. Applied Cognitive Psychology, 17(4), 401-418. http://dx.doi.org/10.1002/acp.877

Levie, W. H., \& Lentz, R. (1982). Effects of text illustrations: A review of research. Education Communication and Technology Journal, 30, 195-232.

Levin, J. R., Anglin, G. J., \& Carney, R. N. (1987). On empirically validating functions of pictures in prose. In D. M. Willows \& H. A. Haughton (Eds.), The psychology of illustration: Volume 1 Basic Research (pp. 51-86). New York, NY: Springer Verlag.

Liu, J. (2004). Effects of comic strips on L2 learners' reading comprehension. TESOL Quarterly, $38(2), 225-243$.

Mason, B., \& Krashen, S. (1997). Can extensive reading help unmotivated students of EFL improve? ITL Review of Applied Linguistics, 117-118, 79-84.

Mayer, R. E., \& Moreno, R. (1998). A split attention effect in multimedia learning: Evidence for dual processing systems in working memory. Journal of Educational Psychology, 90(2), 312-320. http://dx.doi.org/10.1037/0022-0663.90.2.312

Meskill, C. (1996). Listening skills development through multimedia. Journal of Educational Multimedia and Hypermedia, 5(2), 179-201.

Miller, G. A. (1956). The magical number seven, plus or minus two: Some limits on our capacity for processing information. The Psychological Review, 63(2), 81-97. http://dx.doi.org/10.1037/h0043158

Moreno R., \& Mayer, R. E. (1999). Cognitive principles of multimedia learning: The role of modality and contiguity effects. Journal of Educational Psychology, 91, 358-368. http://dx.doi.org/10.1037/0022-0663.91.2.358

Norton, B. (2003). The motivating power of comic books: Insight from Archie comic readers. The Reading Teacher, 57(2), 140-147. 
Takase, A. (2009). The effects of different types of extensive reading materials on reading amount, attitude and motivation. Kinki University, Japan. Retrieved from http://www.seg.co.jp/era/papers/2009-03-takase.pdf

Tindall-Ford, S., Chandler, P., \& Sweller, J. (1997). When two sensory modes are better than one. Journal of Experimental Psychology: Applied, 3(4), 257-287. http://dx.doi.org/10.1037/1076-898X.3.4.257

Ujiie, J., \& Krashen, S. (1996). Comic book reading, reading enjoyment, and pleasure reading among middle class and Chapter I middle school students. Reading Improvement, 33(1), 51-54. 


\section{Appendix A \\ Pre-Project Survey - English Translation}

(Adapted from Furukawa, 2005)

1. I give permission for my results to be used for research purposes (I understand no identifiable information about me will be stored or used).

Yes

No

2. Your daily reading habits in Japanese:
A. Like very much
B. Like
C. Dislike a little
D. Dislike

3. The reason that you like/dislike reading is:

4. Amount of reading you do:
A. I read everyday
B. I read one or two books per week
C. I read a few books a month
D. I don't read much

5. Reading in English
A. Like very much
B. Like
C. Dislike a little
D. Dislike

6. The reason that you like/dislike reading in English is:

7. What part of English do you think you are not good at?
A. Listening
B. Conversation
C. Grammar
D. Reading
E. Composition (writing)
F. Nothing

8. The reason that you think you are not good at this skill is: 
9. Do you think reading in English is necessary?
A. Definitely necessary
B. Probably necessary
C. maybe not necessary
D. Not necessary at all

10. The reason that you think reading in English is necessary/unnecessary is:

11. Please write down what you think about starting the extensive reading program. 


\section{Appendix B \\ Post-Project Survey - English Translation}

(Adapted from Furukawa, 2005)

1. I give permission for my results to be used for research purposes (I understand no identifiable information about me will be stored or used).

Yes

No

2. Your daily reading habits in Japanese:
A. Like very much
B. Like
C. Dislike a little
D. Dislike

3. The reason that you like/dislike reading is:

4. Amount of reading you do:
A. I read everyday
B. I read one or two books per week
C. I read a few books a month
D. I don't read much

5. Reading in English
A. Like very much
B. Like
C. Dislike a little
D. Dislike

6. The reason that you like/dislike reading in English is:

7. What part of English do you think you are not good at?
A. Listening
B. Conversation
C. Grammar
D. Reading
E. Composition (writing)
F. Nothing

8. The reason that you think you are not good at this skill is: 
9. Did you enjoy reading the comic book style readers?
A. Like very much
B. Like
C. Dislike a little
D. Dislike

10. The reason that you liked/disliked reading the comic book style readers is:

11. Please write down any changes that you experienced after starting the extensive reading program.

Changes in attitude:

Changes in your skills:

Changes in your image of reading English:

12. Please write down what you found interesting or helpful about the extensive reading program if you found any: 